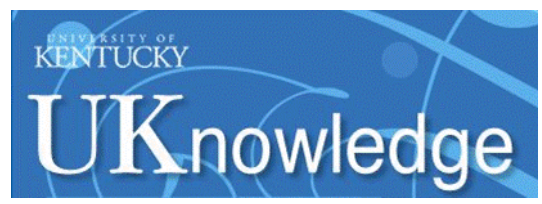

University of Kentucky

UKnowledge

\title{
The Implications of Eco-Evolutionary Processes for the Emergence of Marine Plankton Community Biogeography
}

\author{
Boris Sauterey \\ University of Kentucky, boris.sauterey@uky.edu \\ Ben Ward \\ University of Bristol, UK \\ Jonathan Rault \\ Ifremer, France \\ Chris Bowler \\ Institut national de la santé et de la recherche médicale, France \\ David Claessen \\ Institut national de la santé et de la recherche médicale, France
}

Follow this and additional works at: https://uknowledge.uky.edu/entomology_facpub

Part of the Biology Commons, and the Medicine and Health Sciences Commons

Right click to open a feedback form in a new tab to let us know how this document benefits you.

\section{Repository Citation}

Sauterey, Boris; Ward, Ben; Rault, Jonathan; Bowler, Chris; and Claessen, David, "The Implications of EcoEvolutionary Processes for the Emergence of Marine Plankton Community Biogeography" (2017).

Entomology Faculty Publications. 206.

https://uknowledge.uky.edu/entomology_facpub/206

This Article is brought to you for free and open access by the Entomology at UKnowledge. It has been accepted for inclusion in Entomology Faculty Publications by an authorized administrator of UKnowledge. For more information, please contact UKnowledge@lsv.uky.edu. 


\section{The Implications of Eco-Evolutionary Processes for the Emergence of Marine Plankton Community Biogeography}

\section{Digital Object Identifier (DOI)}

https://doi.org/10.1086/692067

\section{Notes/Citation Information}

Published in The American Naturalist, v. 190, no. 1.

(C) 2017 by The University of Chicago. All rights reserved.

The copyright holder has granted the permission for posting the article here. 


\title{
The Implications of Eco-Evolutionary Processes for the Emergence of Marine Plankton Community Biogeography
}

\author{
Boris Sauterey, ${ }^{1,2, *}$ Ben Ward, ${ }^{3}$ Jonathan Rault ${ }^{4}$ Chris Bowler, ${ }^{1}$ and David Claessen ${ }^{1}$
}

1. Ecole Normale Supérieure, PSL Research University, Institut de Biologie de l'Ecole Normale Supérieure (IBENS), Centre National de la Recherche Scientifique (CNRS) Unité Mixte de Recherche (UMR) 8197, Institut National de la Santé et de la Recherche Médicale (INSERM) U1024, 46 rue d'Ulm, F-75005 Paris, France; 2. Department of Entomology, University of Kentucky, Lexington, Kentucky 40546; 3. School of Geographical Sciences, University of Bristol, University Road, Bristol BS8 1SS, United Kingdom; 4. Ifremer, Unité de Sciences et Technologies Halieutiques, Laboratoire de Technologie et Biologie Halieutique, 8 rue François Toullec, F-56325 Lorient Cedex, France

Submitted February 15, 2016; Accepted February 14, 2017; Electronically published May 8, 2017

Online enhancements: appendixes.

\begin{abstract}
Aвstract: Models of community assembly have been used to illustrate how the many functionally diverse species that compose plankton food webs can coexist. However, the evolutionary processes leading to the emergence of plankton food webs and their interplay with migratory processes and spatial heterogeneity are yet to be explored. We study the eco-evolutionary dynamics of a modeled plankton community structured in both size and space and physiologically constrained by empirical data. We demonstrate that a complex yet ecologically and evolutionarily stable size-structured food web can emerge from an initial set of two monomorphic phytoplankton and zooplankton populations. We also show that the coupling of spatial heterogeneity and migration results in the emergence of specific biogeographic patterns: (i) the emergence of a source-sink structure of the plankton metacommunities, (ii) changes in size diversity dependent on migratory intensity and on the scale at which diversity is considered (local vs. global), and (iii) the emergence of ecoevolutionary provinces (i.e., a spatial unit characterized by some level of abiotic heterogeneity but of homogenous size composition due to horizontal movements) at spatial scales that increase with the strength of the migratory processes.
\end{abstract}

Keywords: plankton biogeography, adaptive dynamics, predator-prey coevolution, evolutionary branching, food webs, metacommunities.

\section{Introduction}

Ocean phytoplankton populations are key components of Earth's biogeochemical cycles. They perform about half of the planetary primary production and sequester large

\footnotetext{
* Corresponding author; e-mail: boris.sauterey@ens.fr. ORCIDs: Ward, http://orcid.org/0000-0003-1290-8270.

Am. Nat. 2017. Vol. 190, pp. 116-130. (c) 2017 by The University of Chicago. 0003-0147/2017/19001-56791\$15.00. All rights reserved. DOI: $10.1086 / 692067$
}

amounts of carbon away from the atmosphere as they sink into the ocean interior (Falkowski and Woodhead 1992; Field et al. 1998; Falkowski et al. 2003). These processes are affected by the composition of plankton communities, with many locally interacting phyto- and zooplankton species associated with a range of different ecological and biogeochemical functions (Le Quere et al. 2005; Guidi et al. 2016). This functional diversity has been shaped by the environmental conditions throughout Earth's history (Katz et al. 2004) and will continue to be so in the future. Although our understanding of how contemporary plankton communities respond to environmental drivers has improved vastly in recent years, key challenges remain when it comes to predicting how evolution may modify these responses in the face of continuing global change. Here we present a step forward in this direction, focusing on the evolution of organism size within an idealized plankton community model. We use this model to study the emergence of (size) diversity as a result of ecological and evolutionary processes in a metacommunity context.

\section{Size, a Key Functional Trait}

Plankton size is distributed over an enormous range, from photosynthetic prokaryotes on the order of $0.1 \mu \mathrm{m}^{3}$ to the largest diatoms as big as $10^{6} \mu \mathrm{m}^{3}$, and it is strongly correlated with a wide range of eco-physiological traits, such that organism size can be used as a proxy for a wide range of important functional characteristics (Cushing 1989; Chisholm 1992; Hansen et al. 1997; Litchman et al. 2007; Andersen et al. 2015). Physiologically, small phytoplankton are excellent competitors for scarce nutrients (Edwards et al. 2012), while some larger plankton benefit from higher 
maximal uptake rates and an increased ability to store excess nutrients (Litchman et al. 2009; Marañón et al. 2013). Ecologically, size regulates zooplankton-phytoplankton trophic interactions, with biomass-specific rates of ingestion by zooplankton generally decreasing with size (Hansen et al. 1997). Smaller zooplankton are also typically associated with predation on smaller prey (Hansen et al. 1994, 1997; Kiorboe 2008), such that smaller phytoplankton are thought to be subject to more intense grazing pressure. Selection pressure on size therefore involves both the abiotic conditions that characterize the local ecosystem (e.g., nutrient supply in interaction with light and temperature) and the ecological dynamics of the plankton community (e.g., predator-prey eco-evolutionary dynamics). Hence, by focusing on size selection, one can capture many aspects of the functional evolution of plankton communities.

\section{Community Assembly}

The species composition and functional role of plankton communities are locally driven in nature by two key mechanisms: (i) species sorting, or the selection of the best competitors among interacting species (Litchman et al. 2012), and (ii) adaptive processes, or the modification of species' traits through time through successive mutation/ selection events (Thomas et al. 2012; Sauterey et al. 2014).

In many plankton models, species sorting as a result of both competitive and predatory interactions is considered the sole driver of community assembly (i.e., without evolution, such that the traits of the competing species are considered fixed; see, e.g., Bruggeman and Kooijman 2007; Follows et al. 2007). Inspired by a general theoretical framework (Hairston et al. 1960; Power 1992), such studies have, for example, shown that both size-dependent physiology and top-down control by grazers appear to contribute to size diversity (Armstrong 1994; Baird and Suthers 2007; Banas 2011; Ward et al. 2014). Resource competition theory (Tilman 1982) defines species competitive ability in term of the minimum resource concentration $\left(R^{*}\right)$ required for their persistence. In the absence of grazing, the best phytoplankton competitor will draw down nutrient concentration to its $R^{*}$, excluding any other species requiring higher nutrient availability to persist. When present, targeted grazing prevents that best phytoplankton competitor to monopolize nutrients by controlling its biomass. Phytoplankton species otherwise excluded due to a higher $R^{*}$ can thus invade, persist, and in turn be subject to topdown control. The nutrient availability is progressively drawn down by those successive invasions until it eventually becomes lower than the $R^{*}$ of any new potential phytoplankton invader (Grover 1994). Within this framework, topdown control restricts the amount of biomass of each species, while the nutrient supply sets the number of coexisting species and total biomass (Armstrong 1994; Price et al. 1994).

On the other hand, a mutation/selection process associated with grazing specificity drives predator-prey coevolution. Typically, the prey adapts to escape the niche of the grazer while the grazer adapts so its niche fits the phenotype of the prey. The selective pressure resulting from that predator-prey coevolution is often disruptive for the prey (e.g., when a grazer optimally grazes prey of a specific size, it is advantageous for the prey to be either larger or smaller than that specific size). Disruptive selection may then promote evolutionary branching events or events of speciation in sympatry, first of the prey and then of the grazer. Models have shown that such events could theoretically allow the evolutionary emergence of complex food webs from just a couple of species (Van Der Laan and Hogeweg 1995; Doebeli and Dieckmann 2000; Loeuille and Loreau 2005; Ito and Ikegami 2006; Brännström et al. 2010).

During the emergence of such communities, ecological and evolutionary processes are clearly intertwined. Ecological dynamics select for the best competitors in the community, while evolutionary adaptation, by introducing new traits, modifies the respective ability of species to compete with each other. This feedback loop is usually referred to as an eco-evolutionary feedback. The timescales of the two processes are typically assumed to be quite separate. However, because of their extremely short generation times and vast populations size, marine plankton exhibit rapid rates of genetic diversification (Bowler et al. 2008) and phenotypical adaptation (Yoshida et al. 2003; Koch et al. 2014). Evolutionary and ecological timescales are thus likely to overlap (at least partially) in plankton communities, increasing the importance of the eco-evolutionary feedback loop for relatively short-term dynamics of marine microbial communities (Yoshida et al. 2003).

\section{The Metacommunity Context}

The eco-evolutionary feedback loop acts locally on a community but may nonetheless be affected by (and affect) other spatially distinct communities connected through spatial dynamics. Such a set of interacting ecosystems, or patches, is known as a metacommunity. As is the case for local community assembly, the metacommunity context appears to act through both abiotic and ecological pathways (D’Ovidio et al. 2010; Barton et al. 2010).

First, the abiotic pathway involves ocean circulation and diffusive processes. These processes, by generating horizontal and vertical movements of water and/or particles, modify the local abiotic environmental conditions (such as temperature or nutrient concentration). This modification of the abiotic environment then affects the fitness of 
the locally competing plankton species. For example, vertical mixing driven by wind increases the local nutrient supply, which in turn positively correlates with phytoplankton biomass and specific diversity (Cermeño et al. 2008). The intensity of vertical mixing - and, hence, of its effect on local abiotic conditions - typically varies in space. In the North Atlantic Ocean, two large regions corresponding to the equator and to the high latitudes are typically characterized by high vertical mixing and, hence, by high nutrient supply, high planktonic biomass, and high diversity. Those two regions at high and low latitudes are separated by the subtropical gyre, a stratified, nutrient-depleted "oceanic desert" characterized by low biomass and low diversity.

Second, horizontal advection and diffusion also bring new competitors/predators into local systems (or export locally adapted species to other places), which modifies the local outcomes of the competitive and adaptive processes. The flux of individuals is more likely to go from the richest biomass patches (sources) to the poorest ones (sinks; Clayton et al. 2013), thus modifying their trait compositions. Because it relies on a biomass differential, this mechanism is usually referred to as "mass effect" in the literature (Holyoak et al. 2005; Urban 2006; Urban et al. 2008). Although diffusive processes typically act on small spatial scales, it has been shown in models of ocean circulation (Barton et al. 2010; Hellweger et al. 2014) and from observations (D'Ovidio et al. 2010) that horizontal transport by advection can connect/isolate water columns separated by anything from a few kilometers to up to thousands of kilometers away from each other. The role played by migration in local communities might be seen as dual (Urban et al. 2008). First, it increases the phenotypical scope on which species sorting applies by locally introducing new traits (often on shorter timescales than that of the mutational process), hence increasing the adaptive potential of the local community. Second, communities that are highly homogenized by water movements might exhibit commonalities in their trait structure and specific composition regardless of their respective abiotic characteristics because the mass effect brings about shared eco-evolutionary history, forming consistent biogeographical units. We use the term "eco-evolutionary province" to refer to such biogeographical units (Martiny et al. 2006).

In this study, we use a community modeling approach, broadly inspired by the conceptual framework of adaptive dynamics (Metz et al. 1992; Geritz et al. 1997), to study the combined effect of ecological (species sorting), mutational, and dispersal processes on the emergence of plankton biogeography. This approach allows us to address three overarching questions related to the emergence of plankton communities: (i) How do ecological interactions, plankton trait evolution, and abiotic conditions interact locally to shape complex food webs? (ii) By reproducing spatial heterogeneity in abiotic forcing, can we reproduce the ecoevolutionary emergence of the geographical patterns of biomass and diversity observed in the oceans (Cermeño et al. 2008)? (iii) Can we simulate the effect of spatial dynamics on those patterns as well as the process of emergence of eco-evolutionary provinces, and what do they imply regarding the adaptive properties of oceanic plankton systems?

\section{Model and Methods}

Model

Our model represents a marine plankton ecosystem by resolving nutrient $(N)$, phytoplankton $(P)$, and zooplankton $(Z)$ dynamics. Plankton populations are characterized by their size, $x_{P}$ and $x_{Z}$, such that their eco-physiological properties can be determined from size-dependent relationships. The biomass distribution in size of $P$ and $Z$ are respectively denoted by $p$ and $z$. The sizes $x_{P}$ and $x_{Z}$ range, respectively, from $0.7 \times 10^{-1}$ to $1.3 \times 10^{4} \mu \mathrm{m}^{3}$ and from $0.7 \times 10^{1}$ to $1.3 \times 10^{6} \mu \mathrm{m}^{3}$ (in computations, $x_{P}$ and $x_{Z}$ are actually defined as the $\log _{10}$ of an individual's volume). We then refer to these ranges as $D_{P}$ and $D_{Z}$, which correspond to the region of the size-dependent parameters in which phytoplankton and zooplankton populations are viable (deduced from preliminary test simulations).

Organisms and nutrients are considered along a single spatial dimension, S. A location on this domain is denoted $s$. The eco-evolutionary dynamics are computationally resolved according to a set of simplifying assumptions: (i) individuals do not change in size during their life, (ii) reproduction is clonal, (iii) advection and diffusion of plankton individuals and nutrients can be described by a diffusion process (these mechanisms are then referred to altogether as horizontal mixing), (iv) the phenotypic effect of mutations is small and can therefore also be approximated by a diffusion process, and (v) the rates of mutation and horizontal mixing are equivalent for all of the individuals (phytoplankton and zooplankton, of any size). These are standard assumptions in an adaptive dynamics conceptual framework and are mostly made for mathematical convenience. They do, however, imply some level of simplification of plankton biology. Note, for example, that sexual reproduction tends to mitigate the effect of selective pressure on trait variation by producing intermediate phenotypes. Assuming that reproduction is clonal only might then overestimate the effect of selective pressure on phenotypical evolution (Dieckmann and Doebeli 1999) even though a very significant proportion of reproduction in plankton communities is attributable to clonal reproduction (e.g., bacterioplankton). The importance of these as- 
sumptions is addressed in "Discussion." According to these assumptions, the dynamics of the size distributions $p$ and $z$ can be described by a reaction-diffusion process (Van Der Laan and Hogeweg 1995; Leimar et al. 2008; Perthame and Gauduchon 2009). The dynamics of $N, p$, and $z$ at location $s$ follows

$$
\begin{aligned}
\frac{\partial N(t, s)}{\partial t}= & r_{N}(N(t, s))+\varphi_{s} \frac{\partial^{2} N(t, s)}{\partial s^{2}}, \\
\frac{\partial p\left(t, s, x_{P}\right)}{\partial t}= & r_{P}\left(t, s, x_{P}\right) p\left(t, s, x_{P}\right)+\varphi_{s} \frac{\partial^{2} p\left(t, s, x_{P}\right)}{\partial s^{2}} \\
& +\varphi_{e} \frac{\partial^{2} p\left(t, s, x_{P}\right)}{\partial x_{P}{ }^{2}}, \\
\frac{\partial z\left(t, s, x_{Z}\right)}{\partial t}= & r_{Z}\left(t, s, x_{Z}\right) z\left(t, s, x_{Z}\right)+\varphi_{s} \frac{\partial^{2} z\left(t, s, x_{Z}\right)}{\partial s^{2}} \\
& +\varphi_{e} \frac{\partial^{2} z\left(t, s, x_{Z}\right)}{\partial x_{Z}{ }^{2}} .
\end{aligned}
$$

The first term of equation (1) is the local change in nutrient concentration through time. Similarly, the first terms of equations (2) and (3), $r_{P}\left(t, s, x_{P}\right)$ and $r_{Z}\left(t, s, x_{Z}\right)$, are the local biomass-controlled (i.e., biomass-specific) net growth rates of phytoplankton and zooplankton populations of size $x_{P}$ and $x_{Z}$. These terms denote the local fitness of plankton individuals. The next terms on the right in equations (1), (2), and (3) are the net fluxes of nutrients and biomass corresponding to individuals of size $x_{P}$ and $x_{Z}$ that arrive and depart from location $s$ as a result of spatial dynamics. The local intensity of spatial dynamics depends on the local geographical gradient of nutrient/biomass and on the rate of horizontal mixing $\varphi_{s}$. Similarly, the last term on the right in equations (2) and (3) is the local net flux in biomass of individuals with phenotypes $x_{P}$ and $x_{Z}$ resulting from the local mutational process, which depends on the local trait distribution and on the mutation rate $\varphi_{e}$.

The rate of change of the local nutrient concentrations $r_{N}(N(t, s))$ from equation (1) results from the balance between nutrient supply and nutrient consumption by the local phytoplankton guild:

$$
\begin{aligned}
& r_{N}(N(t, s))=I\left(N_{0}-N(t, s)\right) \\
& \quad-\int_{D_{P}} \mu_{P}\left(x_{P}\right) \frac{N(t, s)}{N(t, s)+K_{P}\left(x_{P}\right)} p\left(t, s, x_{P}\right) \mathrm{d} x_{P} .
\end{aligned}
$$

Nutrient supply is described by the term $I\left(N_{0}-N(t, s)\right)$, with $I$ being the supply rate and $N_{0}$ the supply point (i.e., the asymptotic nutrient concentration when $N$ is not consumed). $N$ consumption is performed according to a Michaelis-Menten function, with $\mu_{P}\left(x_{P}\right)$ being the sizedependent maximum phytoplankton growth rate and $K_{P}\left(x_{P}\right)$ the size-dependent half-saturation constant. On one hand, based on observations (Marañón et al. 2013) $\mu_{P}$ is maximized for intermediary sizes $\left(\sim 10^{-2} \mu \mathrm{m}^{3}\right.$; fig. $\left.1 A\right)$, likely due to antagonistic physiological size dependences (Marañón et al. 2013; Ward et al. 2017). On the other hand, $K_{P}$ increases with size (Verdy et al. 2009; fig. 1B). Competition for nutrients selects for high $\mu_{P}$ (high maximum growth rate) and low $K_{P}$ (high competitive ability when nutrients are scarce; Healey 1980). There is therefore a trade-off between those two parameters maximized somewhere in between small and intermediary sizes. Total $N$ consumption by phytoplankton is obtained by integrating the effect of each size class over $D_{P}$. Phytoplankton growth can then be described as follows:

$$
\begin{aligned}
r_{P}\left(t, s, x_{P}\right)= & \mu_{P}\left(x_{P}\right) \frac{N(t, s)}{N(t, s)+K_{P}\left(x_{P}\right)} \\
& -\int_{D_{Z}} g\left(x_{P}, x_{Z}, P_{\mathrm{av}}\left(x_{Z}, p(t, s, .)\right)\right) \\
& \times z\left(t, s, x_{Z}\right) \mathrm{d} x_{Z}-m_{P},
\end{aligned}
$$

where $p(t, s,$.$) is the whole size distribution of the phyto-$ plankton community, with the dot referring to the size dimension. The first part of the equation reflects phytoplankton growth through nutrient consumption, the second term describes the biomass loss due to grazing from the zooplankton guild, and the third term $\left(m_{P}\right)$ relates to the phytoplankton basal mortality rate. The strength of the predation interaction between phytoplankton and zooplankton size classes is given by the grazing function $g$. This function depends on the zooplankton predation window $\phi$, a lognormal function of the zooplankton-to-phytoplankton size ratio $\rho$. The size specificity of grazing then relates to $\sigma$, the width of $\phi$ in $\log$ space (see app. A and fig. 1C; Andersen and Beyer 2006; Banas 2011; Ward et al. 2014; apps. A, B are available online). The total availability in prey for a specific zooplankton size class $P_{\mathrm{av}}\left(x_{z}, p(t, s,).\right)$ is then obtained by weighting $\phi$ by the phytoplankton size distribution $p(t, s,$.$) . Note that we assume that prey are phytoplank-$ ton only (i.e., zooplankton do not eat other zooplankton). The function $g$ also depends on the maximum ingestion rate $\mu_{z}\left(x_{z}\right)$, which from observations (Hansen et al. 1997) negatively links to $x_{z}$ (fig. $1 D$ ) and saturates for high $P_{\mathrm{av}}\left(x_{z}, p(t, s,).\right)$. Details on the calculation of $g$ can be found in appendix A. The total effect of the zooplankton guild on one specific phytoplankton size class is obtained by integrating $g$ weighted by the zooplankton size distribution over $D_{Z}$. Zooplankton grazing can be integrated, this time over $D_{P}$, to obtain zooplankton growth as follows:

$$
\begin{aligned}
r_{Z}\left(t, s, x_{Z}\right)= & \int_{D_{P}} g\left(x_{P}, x_{Z}, P_{\mathrm{av}}\left(x_{Z}, p(t, s, .)\right)\right) \\
& \times p\left(t, s, x_{P}\right) \mathrm{d} x_{P}-m_{Z},
\end{aligned}
$$



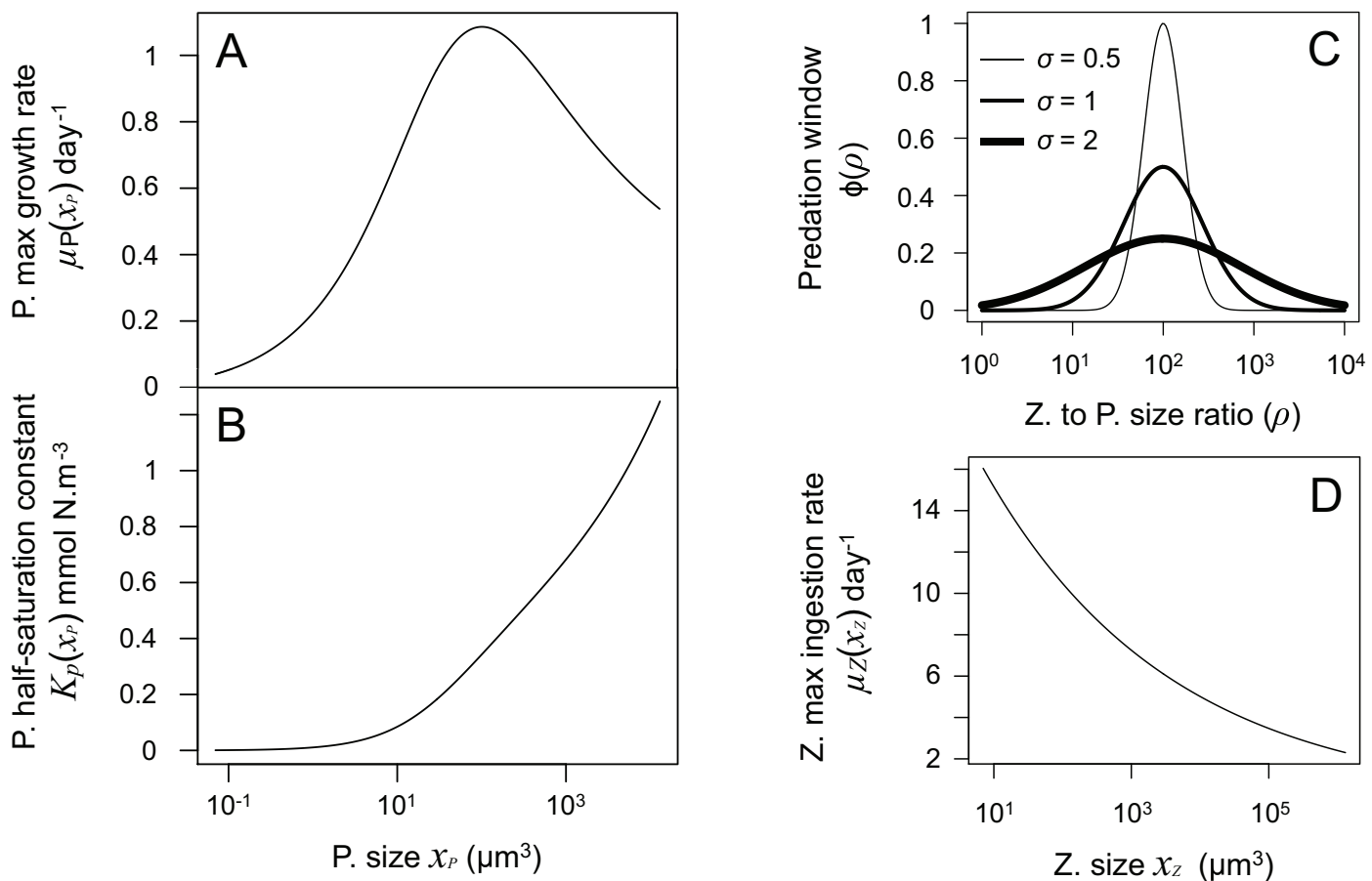

Figure 1: Relationships between the eco-physiological characteristics and size of phytoplankton $x_{P}$ and zooplankton $x_{Z}$. A shows the relation between phytoplankton size $x_{P}$ and maximum growth rate $\mu_{P}$. B shows the positive link between phytoplankton size $x_{P}$ and the half-saturation constant for nutrients $K_{p}$. $C$ shows the predation window $\phi$ depending on the zooplankton-to-phytoplankton biovolume ratio $\rho$ and on its width $\sigma$. D shows the maximum ingestion rate of a zooplankton $\mu_{Z}$ as a decreasing function of its size $x_{z}$.

with $m_{Z}$ being the zooplankton basal mortality rate. Note that the mortality terms $m_{P}$ and $m_{Z}$ include a densitydependent component such that populations of low abundance experience increased mortality (i.e., an Allee effect; Allee et al. 1949). Mutation and horizontal mixing when modeled by diffusion as in our model generate many populations of extremely low abundances, potentially characterized by traits very different from those that dominate the system. These populations (and therefore their traits) can unrealistically emerge in the system if the environmental conditions become favorable to them, generating "evolutionary jumps." We implement an Allee effect following Perthame and Gauduchon (2009) to prevent such events. This Allee effect consists of imposing a high per capita mortality rate to scarce populations so they cannot establish without input from mutational or migratory processes (for the relevant equations, see app. A).

All of the size dependences in the model are derived from empirical measurement (Hansen et al. 1997; Litchman et al. 2009; Verdy et al. 2009; Edwards et al. 2012; Marañón et al. 2013). They can be found in table A1, available online, alongside the size-independent parameters of the model.

\section{Simulation Scenarios and Analysis}

Numerical results are obtained by discretizing the size axis into 200 size classes (app. B). The eco-evolutionary process of community assembly driven by the competition for resources (nutrients or prey) typically results in the emergence of at least one peak in the size distribution of each guild. We consider those peaks as species, characterized by the modal size value of their bell-shaped distribution. The spread in distribution away from that modal value stems from the mutational process, which continuously inserts new (size) diversity into the system. We proceed in three steps to address the questions we are interested in.

First, we investigate the predator-prey coevolutionary dynamics in isolation (i.e., in a single patch, with no spatial dynamics). We initiate the simulations with one phytoplankton and one zooplankton size class with initial sizes at the midpoint of the two logarithmic size ranges (approximately 30 and 3,000 $\mu \mathrm{m}^{3}$, respectively). The single patch is characterized by an initial nutrient concentration $N=N_{0}$. We test the effect of two purely biological parameters on the eco-evolutionary dynamics of the food 
web: (i) $\sigma$, the width of the predation niche, which determines the size specificity of the trophic interaction; and (ii) $\varphi_{e}$, the mutation rate.

Second, we test the effect of the abiotic conditions on the coevolutionary dynamics by varying the supply point $N_{0}$, which corresponds implicitly to variation in the intensity of vertical mixing.

Finally, we introduce horizontal movements resulting from ocean physics by adding the horizontal mixing term. We explicitly simulate the geographical dimension $S$ along which $N_{0}$ varies, allowing movement of nutrients and biomass between patches. The parameter $S$ is discretized into 40 patches (app. B). Hereafter, we use the term "metacommunity" to designate the ensemble of the patches. We test two scenarios (see fig. 2). One consists of a linear gradient in $N_{0}$ along $S$. In the second, we include a nutrient supply gap. This scenario is designed to reflect an idealized ocean basin with two productive regions supported by upwelling and vertical mixing of nutrients into the surface layer (equatorial and high latitudes) interrupted by a subtropical ocean desert, where a downward circulation suppresses the nutrient supply from the nutrient-rich deep waters. These two scenarios allow an evaluation of the effect of the structure of the spatial heterogeneity itself on the emergence of the metacommunity size composition. For the distance in the model to match those of an actual ocean basin, $S$ covers a range of approximately $4,000 \mathrm{~km}$. The initial conditions in each local patch are defined as before (i.e., with two monomorphic guilds and $N=N_{0}$ ).

To quantify the effect of spatial structure and horizontal mixing on diversity patterns, we use species richness (i.e., the number of peaks of local size distributions) as an indi- cator of intrapatch diversity, interpatch diversity, and global diversity ( $\alpha, \beta$, and $\gamma$ diversity, respectively; Whittaker 1972) in the metacommunity. The intrapatch $\alpha$ diversity is the average number of species per patch. The global $\gamma$ diversity is the number of unique species in the whole metacommunity. The interpatch $\beta$ diversity is equal to $(\gamma$ diversity $) /(\alpha$ diversity), thus reflecting the disparity in size composition between the different patches. We use $(\beta \text { diversity })^{-1}$ as an indicator of the similarity between patches or regions. Finally, to quantify the difference between the size distribution of a local system and its local eco-evolutionary attractor, we compute the sum of the absolute differences in biomass for each size class between the local size distribution and the asymptotic size distribution when migratory processes are absent from the model (a time average over the last quarter of the simulations, to account for oscillations).

\section{Results}

\section{Local Coevolution}

In this section, we characterize and describe the purely local eco-evolutionary dynamics of the plankton community, as illustrated in figure $3 A$. First, the initial phytoplankton species increases its competitive ability for scarce nutrient (low $K_{P}$ ) by adapting toward smaller sizes (fig. $3 A$, middle panel). Nutrient concentration hence goes down (fig. 3A, bottom panel). The initial zooplankton species also adapts toward small size (with a slight delay) as a response to the change in size of its prey (fig. $3 A$, top panel). As the zooplankton catch up with their prey, the phyto-

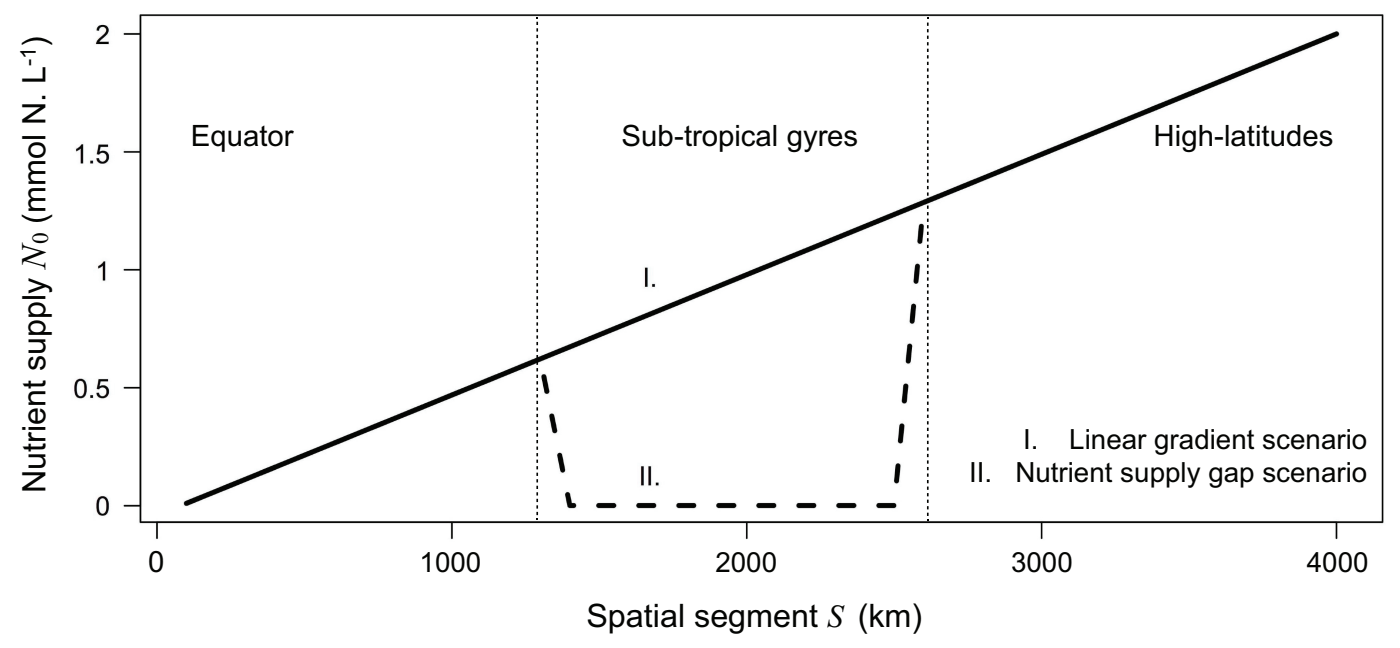

Figure 2: In the linear gradient scenario, $N_{0}$ ranges from 0.01 to $2 \mathrm{mmol} \mathrm{N} . \mathrm{m}^{-3}$. In the nutrient supply gap scenario, $N_{0}$ ranges from 0.01 to $0.6 \mathrm{mmol} \mathrm{N} . \mathrm{m}^{-3}$ in the equatorial region, while it ranges from 1.2 to $2 \mathrm{mmol} \mathrm{N} \cdot \mathrm{m}^{-3}$ in the high-latitude region. These two regions are separated by a subtropical "desert" (1/4 of the segment $S$ ), in which $N_{0}=0.001 \mathrm{mmol} \mathrm{N} \cdot \mathrm{m}^{-3}$. 

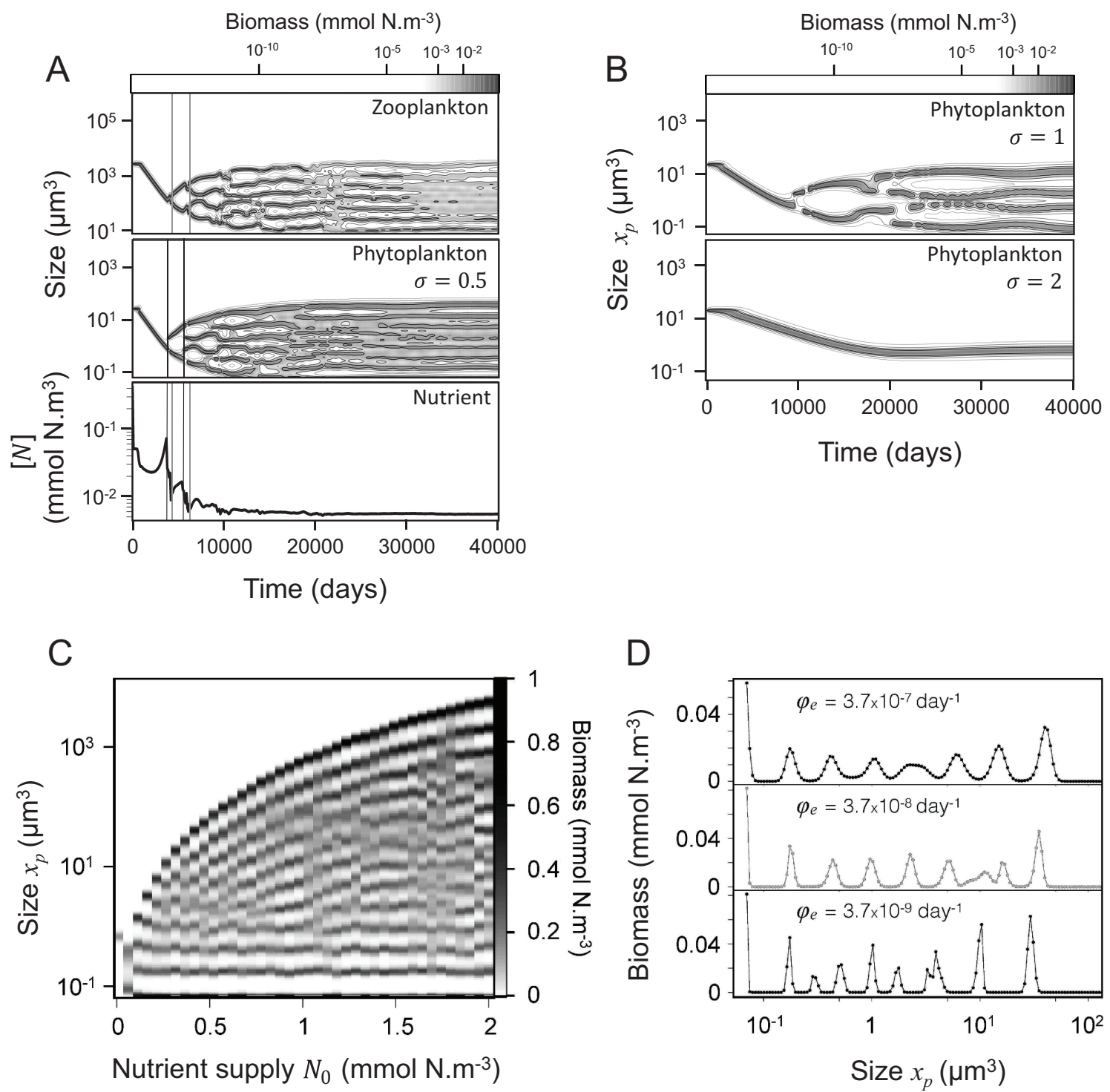

Figure 3: Results of the nonspatial simulations. A, Time series of the size distribution of the zooplankton (top panel) and phytoplankton (middle panel) guilds and of the nutrient concentration $N$ (bottom panel) for one simulation for the default set of parameter values: a mutation rate $\varphi_{e}=3.7 \times 10^{-7} \mathrm{day}^{-1}$, a nutrient supply $N_{0}=0.5 \mathrm{mmol} \mathrm{N} \cdot \mathrm{m}^{-3}$, and a predation window width $\sigma=0.5$. The two vertical black lines denote the two first phytoplankton branching events, and the two gray lines represents those of the zooplankton. Those lines can also be found in the bottom panel to illustrate the effect of the branching on the nutrient concentration $N$. $B$, Time series of the evolution in size of the phytoplankton guild for $\sigma=1$ and 2, with all other parameters being equal to their default value. $C$, Final size distribution of the phytoplankton community for $N_{0}$ ranging from 0.01 to $2 \mathrm{mmol} \mathrm{N} \cdot \mathrm{m}^{-3}$, with all other parameters being equal to their default values. $D$, Snapshot of the size distribution of the phytoplankton community in the final eco-evolutionary attractor for $\varphi_{e}$ ranging from $3.7 \times 10^{-7}$ to $3.7 \times 10^{-9}$ day ${ }^{-1}$, with all other parameters being equal to their default value. The zooplankton guild is not shown in $B-D$ because it mostly mirrors the phytoplankton guild.

plankton are subject to additional mortality induced by the size-specific grazing. As phytoplankton mortality increases, nutrient consumption diminishes and nutrient concentration increases (fig. 3A, bottom panel). Finally, the disruptive potential of the grazing pressure results in the phytoplankton population splitting into two daughter species, each evolving away from the size optimally grazed by the zooplankton population (fig. $3 A$, middle panel, thick black line). The grazing pressure being temporary released, the nutrient consumption goes up again (and, hence, nutrient concentration goes down) until the zooplankton species in turn branches into two species adapted 
to the two new populations of prey (fig. $3 A$, top panel, thick gray line). This double evolutionary branching event then repeats itself, resulting in a progressive size diversification of the food web while the nutrient concentration is progressively drawn down as phytoplankton species are added to the system. The process described here is impacted by three parameters.

First, the cascade of double evolutionary branching events depends on the disruptive potential of the zooplanktonphytoplankton interaction. Figure $3 B$ shows that for higher widths of predation window $\sigma$-hence, when the size specificity of grazing is weak - the number of branching events is small (for $\sigma=1$ ) or even null (for $\sigma=2$ ). Note that we show only phytoplankton dynamics because the zooplankton dynamics mostly reflects the dynamics of their prey. In the latter scenario $(\sigma=2)$, the unique phytoplankton species evolves toward a smaller size that optimizes the trade-off between competitive ability for scarce nutrient maximized for small size $\left(\right.$ low $\left.K_{P}\right)$ and maximum growth rate $\mu_{P}$ maximized for an intermediary size of $10^{2} \mu \mathrm{m}^{3}$ (see fig. $1 A, 1 B$ ). The behavior of the system is then qualitatively similar to simulations without grazers, although the size selected is here slightly larger (as the stronger grazing pressure increases mortality and selects for a larger size with a slightly higher maximum growth rate).

Second, the final number of coexisting species is determined by the nutrient supply $N_{0}$ (fig. $3 C$ ). The process of double evolutionary branching described above progressively draws down nutrient concentration (fig. $3 \mathrm{~A}$, bottom panel). At some point, the nutrient availability becomes lower than the $R^{*}$ of any potential phytoplankton invader, preventing further invasions (Grover 1994). Higher $N_{0}$, by increasing nutrient influx, allows more species of larger size (i.e., farther away from the optimal size described above) and of higher $R^{*}$ to invade before the nutrient availability becomes too low for any further invasion.

Finally, the number of emerging species and their size also depend on mutation rate $\varphi_{e}$ (fig. $3 D$ ). First, the value of $\varphi_{e}$ relates to the width of the size distributions of both phytoplankton and zooplankton species: a lower mutation rate produces narrower size distributions. Zooplankton size affects their resource use (i.e., the phytoplankton size they preferentially graze). Narrower size distributions of zooplankton species therefore result in a narrower consumption niche and, thus, in a release of limiting similarity, which in turn promotes the coexistence of both phytoplankton and zooplankton. Consequently, $\varphi_{e}$ negatively links to the number of species that can coexist in the system, as shown in figure $3 D\left(10\right.$ for $\varphi_{e}=3.7 \times 10^{-9}$ day $^{-1}$, 8 for $\varphi_{e}=3.7 \times 10^{-7}$ day $\left.^{-1}\right)$. Furthermore, when $\varphi_{e}$ is sufficiently low, the quantity of mutants produced by the sole species remains below the survival threshold of the mortality-induced Allee effect (not shown). Therefore, trait evolution does not occur at all.

\section{Linear Nutrient Supply Gradient Scenario}

We now investigate the impact of horizontal mixing by explicitly introducing spatial structure and movement, both resulting from ocean physics. Again, local and spatial zooplankton dynamics mirror those of phytoplankton. The variation in the characteristics of the local systems along the linear gradient of $N_{0}$ (depicted in fig. 2) is similar to that described in the previous section: low $N_{0}$ results in low species richness, smaller sizes (fig. $4 A$, top two panels), and low biomass (fig. 4B). However, horizontal mixing has clear additional effects on the structure of the metacommunity (i.e., the ensemble of the 40 patches). First, horizontal mixing homogenizes the size distribution of the metacommunity, that is, it increases the number of shared species between the patches. For an intermediate value of horizontal mixing $\left(\varphi_{s}=6.25 \times 10^{-6} \mathrm{day}^{-1}\right)$, species in the local patches tend to converge to a limited number of size values, shared over the metacommunity (fig. $4 \mathrm{~A}$, top vs. middle panel). The $\beta$ and $\gamma$ diversities of the metacommunity (i.e., averaged over the 40 patches) consequently negatively link to the rate of horizontal mixing (fig. 4C). Ultimately, for the highest rate of horizontal mixing $\left(\varphi_{s}=6.25 \times 10^{-3}\right.$ day $\left.^{-1}\right)$, local patches are forced toward a globally uniform distribution with the same 11 species (fig. $4 A$, bottom panel; fig. $4 B$, bottom panel) far away from their local eco-evolutionary attractor (fig. $4 D$ ). Those 11 species are therefore locally suboptimal species maintained by horizontal mixing only. Second, for low to intermediate values of $\varphi_{s}$, the migrants increase the species richness of the poorest patches and, consequently, the $\alpha$ diversity of the metacommunity (fig. 4C). Third, above a threshold value $\left(\varphi_{s}>6.25 \times 10^{-5}\right.$ day $\left.^{-1}\right)$, the spatial flux from the richest to the poorest patches leads to a significant loss in both nutrient and biomass from the richest patches (fig. $4 B$ ). In that scenario, although the number of species in the sinks is still increased, it is decreased in the sources (fig. $4 A, 4 B$, bottom panels). This reflects the exclusion of the less competitive species (i.e., larger phytoplankton and zooplankton) from the source patches and, hence, from the metacommunity, whose $\alpha$ diversity then decreases (fig. 4C). Note that the same patterns are observed when the horizontal mixing of nutrient is not accounted for (i.e., the term of spatial diffusion is not applied to the spatial distribution of nutrients in eq. [1]), suggesting that the key factor is a mass effect. Finally, figure $4 D$ shows that when $\varphi_{s}=6.25 \times 10^{-3}$ day $^{-1}$, the divergence of biomass distribution between the metacommunity and its ecoevolutionary attractor without horizontal mixing converges to a value of about $45 \mathrm{mmol} \mathrm{N} \cdot \mathrm{m}^{-2}$ after approximately 

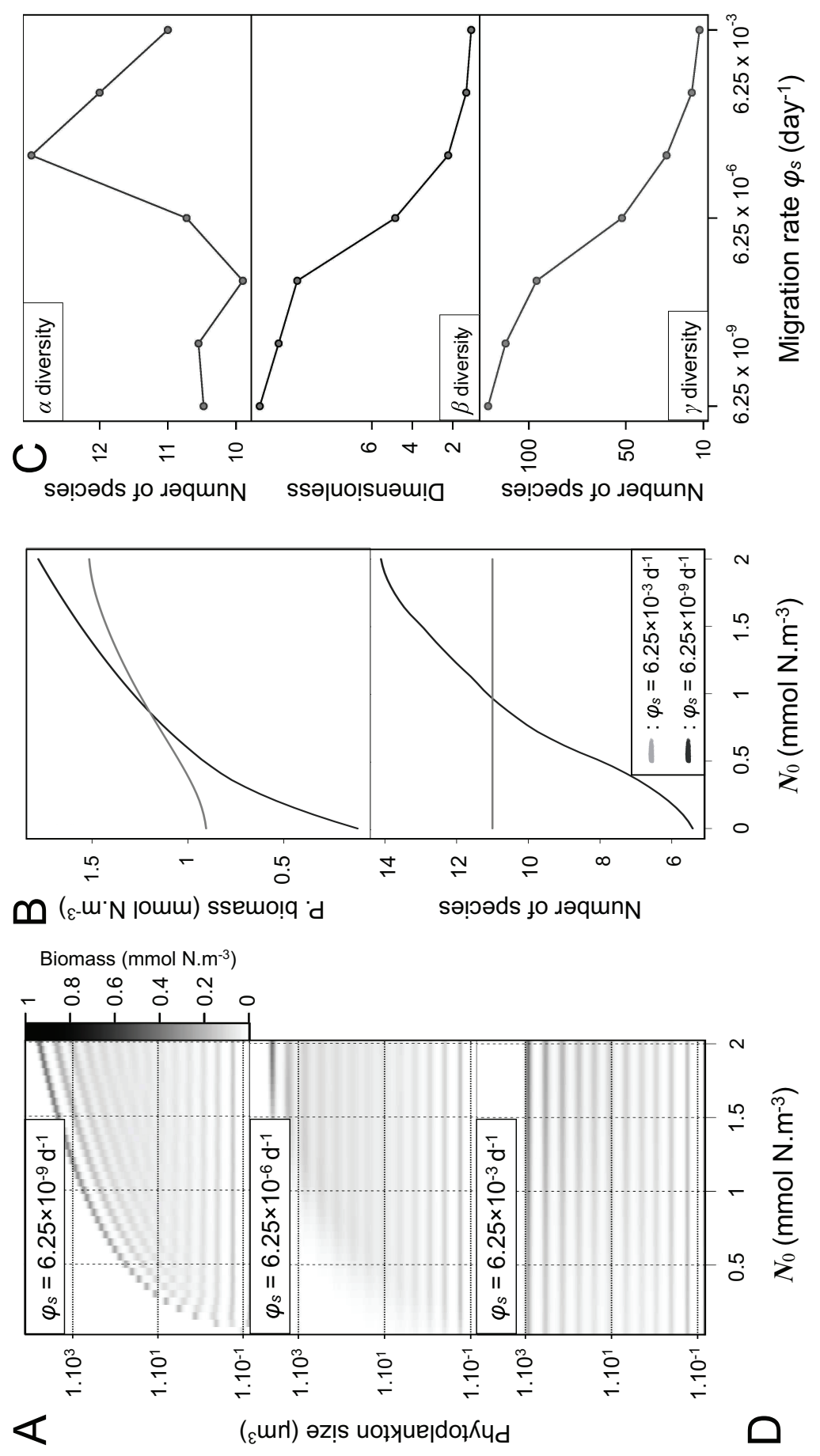

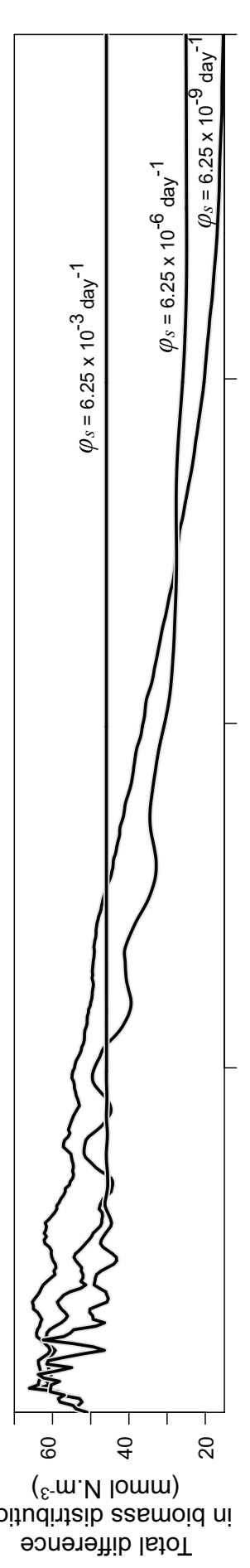

पे च

吾苛

के क्षे

을

중

艺设

के क्ष

हो 11 宁

ㅅำ

웡

군.

쿼

苟昰.

bo

50 $50=5$

$z=0$

a न

유 तै

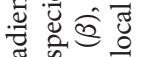

吅

然范

뭉

矛存

o 00

की $\quad 0$ 品:

है $\hat{\sigma} \cdot \tilde{\sigma}$

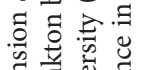

卷苛

唡

可 를

के चु

파웡

कo

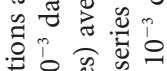

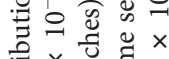

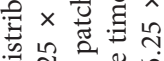

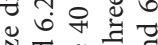

卷 प

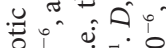

룬어

중

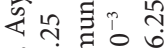

46 응

000

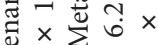

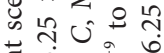

चु U.

플 11

茄导 $\times$

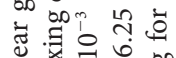

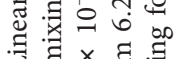

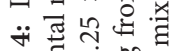

+ि 
7,000 days. By contrast, for the lowest value of horizontal mixing intensity $\left(\varphi_{s}=6.25 \times 10^{-6} \mathrm{day}^{-1}\right)$ this divergence converges to a lower value of less than $20 \mathrm{mmol} \mathrm{N.m}{ }^{-2}$ after more than 40,000 days. There is therefore an emergent trade-off between the speed of trait selection and the optimality of the trait selected: migration increases the range of traits on which competitive sorting applies, hence making local trait selection faster while maintaining locally suboptimal traits.

\section{Nutrient Supply Gap Scenario}

We now use the nutrient supply gap scenario (fig. 2) to investigate the combined effect of spatial structure (here the existence of a geographical barrier) and spatial dynamics on the emergence of plankton biogeography in the oceans. We measure the level of similarity (as $[\beta \text { diversity }]^{-1}$ ) inside and between the two productive regions (equator and high latitudes; fig. 2). We first measure the basal level of those two indicators (i.e., without horizontal mixing). Then we look at the effect of the value of the rate of horizontal mixing. Figure 5 shows the results rescaled between 0 (for their respective basal level) and 1 (for 100\% of similarity) to help comparison. Intraregion similarity increases gradually with horizontal mixing intensity as

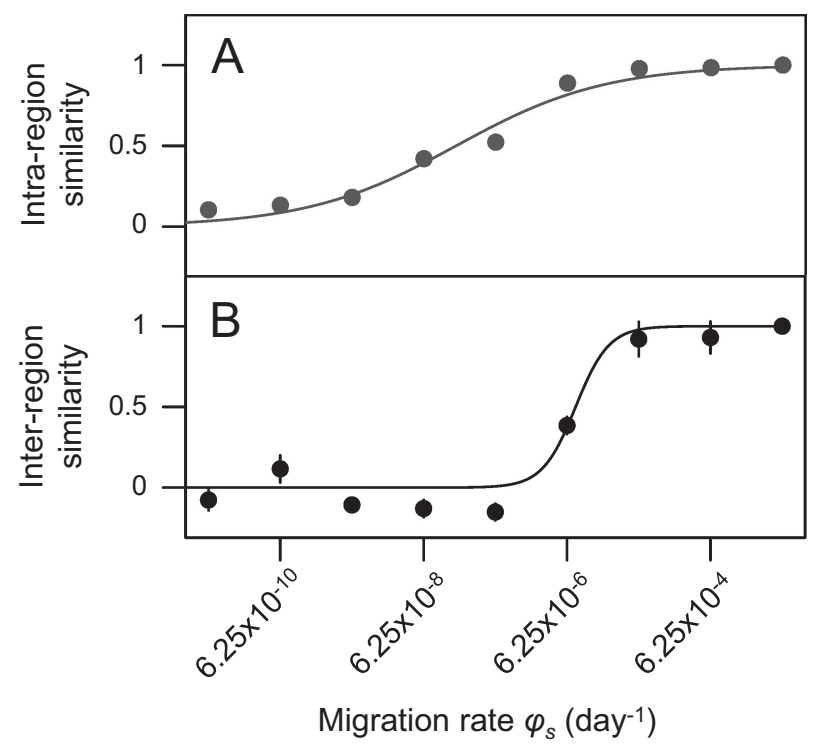

Figure 5: $A$, Average of the intraregion similarities (calculated as $[\beta$ diversity $]^{-1}$ ) of the equatorial and high-latitude regions for a rate of horizontal mixing $\varphi_{s}$ ranging from $6.25 \times 10^{-11}$ to $6.25 \times 10^{-3}$ day $^{-1}$. $B$, Interregion similarity for the same values of $\varphi_{s}$. Each point in $A$ and $B$ is the average through time of the indicator for the last 24,000 days of a simulation of 120,000 days. The vertical bars represent the standard deviation from this average during that period of time. Sigmoid fits have been superimposed to the points to help visualize the trends. migrants homogenize the size distribution inside each region (fig. 5A). By contrast, the change in interregion similarity with horizontal mixing intensity is much more bimodal. For $\varphi_{s}<6.25 \times 10^{-6}$ day $^{-1}$, the migrants cannot overcome the Allee effect while crossing the geographical barrier, and homogenization is not observed (fig. 5B). After that threshold value, the increase in the interregion similarity is sharp (compared with that of the intraregion similarity). Hence, for the same spatial structure in nutrient supply, the metacommunity can exhibit independent patches for low levels of horizontal mixing, can be divided into two eco-evolutionary provinces that are isolated from one another by the geographical barrier but that exhibit high-level internal similarity despite their abiotic heterogeneities for intermediate levels of horizontal mixing, or can be fully homogenized in a unique eco-evolutionary province despite the geographical barrier for high levels of horizontal mixing.

\section{Discussion}

\section{Local Emergence of Plankton Communities}

The predictions of our model illustrate that size-specific grazing, in addition to stabilizing size diversity in plankton communities, can also drive the eco-evolutionary emergence of diversity in local planktonic communities (fig. $3 A$ ). As raised in the introduction, Hairston et al. (1960), Power (1992), Grover (1994), and Armstrong (1994) have hypothesized that trait-specific grazing regulates the maximum population size of individual species (top down), while the total biomass - and, hence, the overall diversity-remains controlled by bottom-up processes (the supply of basal nutrients to the system). Size-specific grazing has been used in models of different levels of complexity to explain and reproduce the observed ecological stability of size diversity in plankton communities (Armstrong 1994; Baird and Suthers 2007; Banas 2011; Ward et al. 2014). The novelty of our work is that we illustrate how plankton diversity might emerge from local eco-evolutionary processes in an idealized isolated ecosystem (fig. 3) inspired by the existing literature on predator-prey coevolution (Van Der Laan and Hogeweg 1995; Doebeli and Dieckmann 2000; Loeuille and Loreau 2005; Ito and Ikegami 2006; Brännström et al. 2010) and using a model based on empirical data (Litchman et al. 2009; Edwards et al. 2012; Marañón et al. 2013), which allows us to relate our results to known biological aspects of such systems.

First, the size specificity of the grazing pressure, which is inversely related to the width of the grazing niche $\sigma$, results in the disruptive potential of zooplankton-phytoplankton coevolution. Interestingly, this parameter also relates to the limiting similarity between zooplankton (MacArthur and 
Levins 1967): a high $\sigma$ corresponds to a higher similarity in the resources (i.e., phytoplankton) consumed by zooplankton of different sizes and therefore prevents coexistence (fig. 3A, lower panel). A low $\sigma$ has thus a dual enhancing effect on size diversity, on the phytoplankton guild (high disruptive potential of grazing), and on the zooplankton guild (low limiting similarity).

The value of the mutation rate $\varphi_{e}$ modifies the final size distribution or, if sufficiently small, impedes any evolutionary dynamics. The first effect results from mutations generating the bell shape of the biomass distribution of each species: peaks are narrower for low mutation rates (i.e., species are less phenotypically diverse; fig. 3C). Narrower phytoplankton size distributions tighten the zooplankton size distributions, relaxing limiting similarity between zooplankton species and allowing more species to coexist. The effect is, however, subtle: a variation of two orders of magnitude in the mutation rate $\varphi_{e}$ leads to an increase in the species number from 8 to 10 . The second effect is that below a threshold value of $\varphi_{e}$ the production of mutants becomes too low to counteract the Allee effect (density-dependent mortality) that characterizes population dynamics in the model. This illustrates the intuitive idea that in an evolutionary context a community can adapt only if the mutational process produces a sufficient amount of diversity for natural selection to act on (Claessen et al. 2007). The motivation for exploring the large range of values of mutation rate in the present study stems from the lack of a clear evaluation of the speed of plankton phenotypical changes. Although the scarcity of empirical data explains part of that deficit, the absence of a proper identification of the underlying mechanisms (e.g., mutation, plasticity, epigenetics) and of their relative importance (especially from one species to another) is another difficulty. To further resolve the adaptive properties of plankton communities, it is therefore essential to quantify and understand the evolution of key functional traits (like size) in various phytoplankton species (see, e.g., Lohbeck et al. 2012).

In an idealized isolated ecosystem, a plankton community is therefore characterized by an eco-evolutionary "diversification potential" depending on the grazing specificity (negatively linked to $\sigma$ ) and on the mutation rate $\varphi_{e}$ of its plankton individuals. The bottom-up limitation by $N_{0}$ of the local emergence of diversity (fig. $3 B$ ) illustrates the importance of abiotic factors (here vertical mixing) in controlling the realization of that diversification potential.

Note that these results are obtained by making assumptions that strongly simplify plankton ecology: (i) no individual growth/development, (ii) clonal reproduction, (iii) horizontal mixing as a diffusive process, (iv) mutational process as a diffusive process, and (v) constant mutation and migration rates among size and trophic layers. Their potential effects on the predictions of the model should, however, be investigated. As stated previously, sexual reproduction could, for example, mitigate the disruptive and directional selection resulting from predator-prey coevolution, unless mating is assortative (Dieckmann and Doebeli 1999). Moreover, releasing the assumption of constant mutation rate over size and trophic levels might affect the predictions of our model (e.g., small organisms tend in nature to evolve faster and exhibit higher trait diversity due to larger population sizes and shorter generation times; Gillooly 2000; Gillooly et al. 2005). The current work also neglects plankton ontogeny, although it has been documented as an important modifier of phyto- and zooplankton resource use through allometric scaling of their consumption rate (Hansen and Ockelmann 1991; Jewson 1992) or through ontogenic niche shift (Poulet 1977) and therefore likely modifies population dynamics in a context of predator-prey interactions (Persson et al. 1998; Claessen and Dieckmann 2002). We argue that these assumptions, common in both models of plankton community and models of trait evolution, must be investigated in situ, in vitro, and in silico to evaluate how much they diverge from the reality of planktonic systems and how much these divergences actually affect our current understanding of planktonic systems.

\section{Taking the Metacommunity Context into Account}

We use a simplistic representation of ocean physics to mimic its effect on plankton communities: vertical mixing and upwelling are represented through heterogeneity in nutrient supply, while both nutrients and individuals are dispersed as a result of horizontal mixing. Our results highlight the importance of taking into account the interaction between the local eco-evolutionary process and spatial dynamics to understand the adaptive properties of marine microbial communities.

First, this representation allows us to re-create the positive correlation between diversity and nutrient supply resulting from vertical mixing observed in the ocean ( $\mathrm{Li}$ 2002; Cermeño et al. 2008) and reproduced in other plankton community models (Vallina et al. 2014; Ward et al. 2014; fig. $4 A, 4 B$ ). Note, however, that this positive relationship can be reversed for systems exhibiting seasonal blooms, which cannot be reproduced in the model because of our assumption of steady nutrient supply. In such systems, phytoplankton biomass increases by bursts, and top-down control cannot act as efficiently as a diversity maintenance mechanism because the increase in zooplankton biomass is not immediate (Irigoien et al. 2004; Vallina et al. 2014). Second, by considering horizontal mixing, our model reproduces a metacommunity context in which nutrient supply heterogeneity and migration result in 
a source-sink structure of biomass and diversity (fig. 4B). Phenotypically richer communities in the nutrient-richest patches provide the poorer parts of the metacommunity with migrants through the mass effect and therefore modify their local trait compositions. The mass effect, depending on its intensity, either (i) increases diversity through import of individuals into the poorest patches (fig. $4 C$, top panel), (ii) decreases it through homogenization (a classical effect of migration; see Mouquet and Loreau 2003; Holyoak et al. 2005; Urban et al. 2008; fig. 4C, middle and bottom panels), or (iii) decreases it by causing a sufficient loss of biomass in the richest patches for the rarest phenotypes (larger plankton) to become extinct (fig. $4 A$, bottom panel; fig. $4 B$; fig. $4 C$, top panel).

Interestingly, the intensity of the mass effect also affects the speed at which the metacommunity assembles. When horizontal mixing is absent or weak, local patches will adapt slowly toward their local eco-evolutionary equilibrium following the sole mutation/selection process. When horizontal mixing is stronger, communities adapt faster toward a final trait distribution that might, however, be very different from the local eco-evolutionary attractor (fig. 4D). This is attributable to the introduction of new phenotypes resulting in the persistence of maladapted species. Our work thus highlights the existence of a trade-off between speed and optimality of the adaptive process, as hypothesized in previous studies (Urban 2006; Urban et al. 2008), and, in general, the importance of the interaction between migration and local adaptive processes for the adaptive responses of metacommunities (Brockhurst et al. 2003; Forde et al. 2004). This question might be crucial in instances where perturbations of different frequencies and amplitudes are considered. Typically, fast-adapting metacommunities are likely to be more suited to systems that are frequently but mildly disturbed, while optimally adapting metacommunities would respond more efficiently to more continuous, stronger perturbations. Furthermore, Smith et al. (2016) show in a modeling study that the same trade-off also emerges as a result of the mutational process, which illustrates that the trade-off relates to the generation of diversity in general and not to one process of diversity generation specifically.

We also reproduce the spatial structure of the North Atlantic transect (Cermeño et al. 2008): an equatorial and a high-latitude region characterized by relatively high nutrient supply exhibiting high total biomass and biodiversity, separated by a subtropical oceanic desert (fig. 2). Depending on the level of horizontal mixing, migration may or may not homogenize the size composition inside each region (fig. $5 A$ ) and may or may not bridge the geographical barrier that is the subtropical gyre (fig. $5 B$ ). Depending on the rate of horizontal mixing, the transect may end up with a very different number of distinct eco-evolutionary provinces. There could be a unique province for each spatial location when horizontal mixing is very low, or there could be just one eco-evolutionary province covering the whole transect when horizontal mixing is sufficient to bridge the subtropical gyre. In between, for intermediate values of horizontal mixing, we might see two distinct eco-evolutionary provinces at the equator and at high latitudes (themselves homogenized by an internal mass effect). When the transect exhibits two provinces, each of them has a distinct eco-evolutionary history ultimately resulting in two distinct trait compositions. This might be key to understanding the way functional traits (size but also temperature-related traits, nutrient-acquisition strategies, and so on) spread in the ocean: the fact that a trait provides a competitive advantage in certain environmental conditions is not sufficient for it to invade the entire ocean because this new trait must also have the possibility of reaching the areas where these environmental conditions are encountered. This idea may explain the existence in the ocean of so many functionally similar but phylogenetically distinct phytoplankton species (Hellweger et al. 2014): for a specific trait to appear in two completely isolated but similar regions, two independent evolutionary processes of variation and selection have to occur.

This view of the way plankton communities assemble contradicts the idea that "everything is everywhere but the environment selects" (Baas Becking 1934), which dominates the conceptual landscape in current ocean microbial ecology (Follows et al. 2007; O’Malley 2007). This alternative view relies not only on the geographical distribution of abiotic conditions and its effect on competitive sorting but also on the interplay between local eco-evolutionary adaptation and migration. Once coupled to a realistic representation of ocean physics, as provided by general circulation models, an eco-evolutionary model of plankton communities might help to identify actual eco-evolutionary provinces and therefore characterize the typical timescales of adaptive responses of plankton communities to future environmental changes. An intriguing opportunity to explore this dimension of phytoplankton diversity would be to compare results obtained in general circulation models that include an eco-evolutionary model of plankton community with data obtained from sampling cruises, such as the Tara Oceans expeditions (Bork et al. 2015; Pesant et al. 2015).

\section{Acknowledgments}

We thank S. R. Hall, who, thanks to his insightful comments, greatly contributed to the improvement of the readability of this article. D.C., C.B., B.S., and J.R. received financial support from the French National Research Agency through project ANR-10-BLAN-1709 PHYTBACK. D.C. 
and C.B. received financial support from the French Government "Investissements d'Avenir" programs MEMO LIFE (ANR-10-LABX-54) and PSL Research University (ANR-11-IDEX-0001-02). C.B. received funding from the European Research Council (ERC) Advanced Award "Diatomite," the Louis D Foundation, and the Gordon and Betty Moore Foundation.

\section{Literature Cited}

Allee, W., O. Park, A. Emerson, T. Park, and K. Schmidt. 1949. Principles of animal ecology. W. B. Saunders, Philadelphia.

Andersen, K., D. Aksnes, T. Berge, Ø. Fiksen, and A. Visser. 2015 Modelling emergent trophic strategies in plankton. Journal of Plankton Research 37:862-868.

Andersen, K., and J. Beyer. 2006. Asymptotic size determines species abundance in the marine size spectrum. American Naturalist 168:54-61.

Armstrong, R. 1994. Grazing limitation and nutrient limitation in marine ecosystems: steady state solutions of an ecosystem model with multiple food chains. Limnology and Oceanography 39: 597-608.

Baas Becking, L. 1934. Geobiologie of inleiding tot de milieukunde. W. P. Van Stockum \& Zoon, The Hague.

Baird, M., and I. Suthers. 2007. A size-resolved pelagic ecosystem model. Ecological Modelling 203:185-203.

Banas, N. 2011. Adding complex trophic interactions to a sizespectral plankton model: emergent diversity patterns and limits on predictability. Ecological Modelling 222:2663-2675.

Barton, A., S. Dutkiewicz, G. Flierl, J. Bragg, and M. Follows. 2010. Patterns of diversity in marine phytoplankton. Science 327:1509-1511.

Bork, P., C. Bowler, C. De Vargas, G. Gorsky, E. Karsenti, and P. Wincker. 2015. Tara Oceans studies plankton at planetary scale. Science 348:873.

Bowler, C., A. Allen, J. Badger, J. Grimwood, K. Jabbari, A. Kuo, U. Maheswari, et al. 2008. The Phaeodactylum genome reveals the evolutionary history of diatom genomes. Nature 456:239-244.

Brännström, A.., N. Loeuille, M. Loreau, and U. Dieckmann. 2010. Emergence and maintenance of biodiversity in an evolutionary food-web model. Theoretical Ecology 4:467-478.

Brockhurst, M., A. Morgan, P. Rainey, and A. Buckling. 2003. Population mixing accelerates coevolution. Ecology Letters 6:975-979.

Bruggeman, J., and S. Kooijman. 2007. A biodiversity-inspired approach to aquatic ecosystem modeling. Limnology and Oceanography 52:1533-1544.

Cermeño, P., S. Dutkiewicz, R. Harris, M. Follows, O. Schofield, and P. Falkowski. 2008. The role of nutricline depth in regulating the ocean carbon cycle. Proceedings of the National Academy of Sciences of the USA 105:20344-20349.

Chisholm, S. 1992. Phytoplankton size. Pages $213-237$ in P. G. Falkowski and A. D. Woodhead, eds. Primary productivity and biogeochemical cycles in the sea. Vol. 43. Environmental Science Research. Plenum, New York.

Claessen, D., J. Andersson, L. Persson, and A. de Roos. 2007. Delayed evolutionary branching in small populations. Evolutionary Ecology Research 9:51-69.

Claessen, D., and U. Dieckmann. 2002. Ontogenetic niche shifts and evolutionary branching in size-structured populations. Evolutionary Ecology Research 4:189-217.
Clayton, S., S. Dutkiewicz, O. Jahn, and M. Follows. 2013. Dispersal, eddies, and the diversity of marine phytoplankton. Limnology and Oceanography 3:182-197.

Cushing, D. 1989. A difference in structure between ecosystems in strongly stratified waters and in those that are only weakly stratified. Journal of Plankton Research 11:1-13.

D’Ovidio, F., S. De Monte, S. Alvain, Y. Dandonneau, and M. Lévy. 2010. Fluid dynamical niches of phytoplankton types. Proceedings of the National Academy of Sciences of the USA 107:1836618370.

Dieckmann, U., and M. Doebeli. 1999. On the origin of species by sympatric speciation. Nature 400:354-357.

Doebeli, M., and U. Dieckmann. 2000. Evolutionary branching and sympatric speciation caused by different types of ecological interactions. American Naturalist 156:S77-S101.

Edwards, K., M. Thomas, C. Klausmeier, and E. Litchman. 2012. Allometric scaling and taxonomic variation in nutrient utilization traits and maximum growth rate of phytoplankton. Limnology and Oceanography 57:554-566.

Falkowski, P., E. Laws, R. Barber, and J. Murray. 2003. Phytoplankton and their role in primary, new, and export production. Pages 99-121 in M. J. R. Fasham, ed. Ocean biogeochemistry. Springer, Berlin.

Falkowski, P., and A. Woodhead. 1992. Primary productivity and biogeochemical cycles in the sea. Vol. 43. Environmental Science Research. Plenum, New York.

Field, C., M. Behrenfeld, J. Randerson, and P. Falkowski. 1998. Primary production of the biosphere: integrating terrestrial and oceanic components. Science 281:237-240.

Follows, M., S. Dutkiewicz, S. Grant, and S. Chisholm. 2007. Emergent biogeography of microbial communities in a model ocean. Science 315:1843-1846.

Forde, S., J. Thompson, and B. Bohannan. 2004. Adaptation varies through space and time in a coevolving host-parasitoid interaction. Nature 431:841-844.

Geritz, S., J. Metz, E. Kisdi, and G. Meszéna. 1997. Dynamics of adaptation and evolutionary branching. Physical Review Letters 78 2024-2027.

Gillooly, J. 2000. Effect of body size and temperature on generation time in zooplankton. Journal of Plankton Research 22:241-251.

Gillooly, J., A. Allen, G. West, and J. Brown. 2005. The rate of DNA evolution: effects of body size and temperature on the molecular clock. Proceedings of the National Academy of Sciences of the USA 102:140-145.

Grover, J. 1994. Assembly rules for communities of nutrient-limited plants and specialist herbivores. American Naturalist 143:258-282.

Guidi, L., S. Chaffron, L. Bittner, D. Eveillard, A. Larhlimi, S. Roux, Y. Darzi, et al. 2016. Plankton networks driving carbon export in the oligotrophic ocean. Nature 532:465-470.

Hairston, N., F. Smith, and L. Slobodkin. 1960. Community structure, population control, and competition. American Naturalist 94:421-425.

Hansen, B., P. Bjørnsen, and P. Hansen. 1994. The size ratio between planktonic predators and their prey. Limnology and Oceanography 39:395-403.

1997. Zooplankton grazing and growth: scaling within the $2-2,000-\mu \mathrm{m}$ body size range. Limnology and Oceanography 42 : $687-704$.

Hansen, B., and K. Ockelmann. 1991. Feeding behaviour in larvae of the opisthobranch Philine aperta. I. Growth and functional re- 
sponse at different developmental stages. Marine Biology 111: 255-261.

Healey, F. 1980. Slope of the Monod equation as an indicator of advantage in nutrient competition. Microbial Ecology 5:281-286.

Hellweger, F., E. van Sebille, and N. Fredrick. 2014. Biogeographic patterns in ocean microbes emerge in a neutral agent-based model. Science 345:1346-1349.

Holyoak, M., M. Leibold, and R. Holt. 2005. Metacommunities: spatial dynamics and ecological communities. University of Chicago Press, Chicago.

Irigoien, X., J. Huisman, and R. Harris. 2004. Global biodiversity patterns of marine phytoplankton and zooplankton. Nature 429: 863-867.

Ito, H., and T. Ikegami. 2006. Food-web formation with recursive evolutionary branching. Journal of Theoretical Biology 238:1-10.

Jewson, D. 1992. Size reduction, reproductive strategy and the life cycle of a centric diatom. Philosophical Transactions of the Royal Society B 336:191-213.

Katz, M., Z. Finkel, and D. Grzebyk. 2004. Evolutionary trajectories and biogeochemical impacts of marine eukaryotic phytoplankton. Annual Review of Ecology, Evolution, and Systematics 35:523-556.

Kiorboe, T. 2008. A mechanistic approach to plankton ecology. Princeton University Press, Princeton, NJ.

Koch, H., J. Frickel, M. Valiadi, and L. Becks. 2014. Why rapid, adaptive evolution matters for community dynamics. Frontiers in Ecology and Evolution 2:1-10.

Le Quere, C., S. Harrison, C. Prentice, E. Buitenhuis, O. Aumont, L. Bopp, H. Claustre, et al. 2005. Ecosystem dynamics based on plankton functional types for global ocean biogeochemistry models. Global Change Biology 11:2016-2040.

Leimar, O., M. Doebeli, and U. Dieckmann. 2008. Evolution of phenotypic clusters through competition and local adaptation along an environmental gradient. Evolution 62:807-822.

Li, W. 2002. Macroecological patterns of phytoplankton in the northwestern North Atlantic Ocean. Nature 419:154-157.

Litchman, E., K. Edwards, C. Klausmeier, and M. Thomas. 2012. Phytoplankton niches, traits and eco-evolutionary responses to global environmental change. Marine Ecology Progress Series 470:235248.

Litchman, E., C. Klausmeier, O. Schofield, and P. Falkowski. 2007. The role of functional traits and trade-offs in structuring phytoplankton communities: scaling from cellular to ecosystem level. Ecology Letters 10:1170-1181.

Litchman, E., C. Klausmeier, and K. Yoshiyama. 2009. Contrasting size evolution in marine and freshwater diatoms. Proceedings of the National Academy of Sciences of the USA 106:2665-2670.

Loeuille, N., and M. Loreau. 2005. Evolutionary emergence of sizestructured food webs. Proceedings of the National Academy of Sciences of the USA 102:5761-5766.

Lohbeck, K., U. Riebesell, and T. Reusch. 2012. Adaptive evolution of a key phytoplankton species to ocean acidification. Nature Geoscience 5:1-6.

MacArthur, R., and R. Levins. 1967. The limiting similarity, convergence, and divergence of coexisting species. American Naturalist 101:377-385.

Marañón, E., P. Cermeño, D. López-Sandoval, T. Rodríguez-Ramos, C. Sobrino, M. Huete-Ortega, J. Blanco, et al. 2013. Unimodal size scaling of phytoplankton growth and the size dependence of nutrient uptake and use. Ecology Letters 16:371-379.
Martiny, J., B. Bohannan, J. Brown, M. Kane, J. Krumins, C. Kuske, P. Morin, et al. 2006. Microbial biogeography: putting microorganisms on the map. Nature Reviews Microbiology 4:102-113.

Metz, J., R. Nisbet, and S. Geritz. 1992. How should we define "fitness" for general ecological scenarios? Trends in Ecology and Evolution 7:198-202.

Mouquet, N., and M. Loreau. 2003. Community patterns in sourcesink metacommunities. American Naturalist 162:544-557.

O'Malley, M. 2007. The nineteenth century roots of "everything is everywhere." Natures Reviews Microbiology 5:647-651.

Persson, L., K. Leonardsson, A. de Roos, M. Gyllenberg, and B. Christensen. 1998. Ontogenetic scaling of foraging rates and the dynamics of a size-structured consumer-resource model. Theoretical Population Biology 54:270-293.

Perthame, B., and M. Gauduchon. 2009. Survival thresholds and mortality rates in adaptive dynamics: conciliating deterministic and stochastic simulations. Mathematical Medicine and Biology 27:195-210.

Pesant, S., F. Not, M. Picheral, S. Kandels-Lewis, N. Le Bescot, G. Gorsky, D. Iudicone, et al. 2015. Open science resources for the discovery and analysis of Tara Oceans data. Scientific Data 2: 150023.

Poulet, S. 1977. Grazing of marine copepod developmental stages on naturally occurring particles. Journal of the Fisheries Board of Canada 34:2381-2387.

Power, M. 1992. Top-down and bottom-up forces in food webs: do plants have primacy? Ecology 73:733-746.

Price, N., B. Ahner, and F. Morel. 1994. The equatorial Pacific Ocean: grazer-controlled phytoplankton populations in an ironlimited ecosystem. Limnology and Oceanography 39:520-534.

Sauterey, B., B. Ward, M. Follows, C. Bowler, and D. Claessen. 2014. When everything is not everywhere but species evolve: an alternative method to model adaptive properties of marine ecosystems. Journal of Plankton Research 36:1-20.

Smith, S., S. Vallina, and A. Merico. 2016. Functional diversity mediates an emergent trade-off in the response of phytoplankton communities to rare versus frequent disturbances. Scientific Reports 6:34170.

Thomas, M., C. Kremer, C. Klausmeier, and E. Litchman. 2012. A global pattern of thermal adaptation in marine phytoplankton. Science 338:1085-1088.

Tilman, D. 1982. Resource competition and community structure. Monographs in Population Biology. Princeton University Press, Princeton, NJ.

Urban, M. 2006. Maladaptation and mass effects in a metacommunity: consequences for species coexistence. American Naturalist 168:28-40.

Urban, M., M. Leibold, P. Amarasekare, L. De Meester, R. Gomulkiewicz, M. Hochberg, C. Klausmeier, et al. 2008. The evolutionary ecology of metacommunities. Trends in Ecology and Evolution 23: 311-317.

Vallina, S., M. Follows, S. Dutkiewicz, J. Montoya, P. Cermeño, and M. Loreau. 2014. Global relationship between phytoplankton diversity and productivity in the ocean. Nature Communications 5:4299.

Van Der Laan, J., and P. Hogeweg. 1995. Predator-prey coevolution: interactions across different timescales. Proceedings of the Royal Society B 259:35-42.

Verdy, A., M. Follows, and G. Flierl. 2009. Optimal phytoplankton cell size in an allometric model. Marine Ecology Progress Series 379:1-12. 
Ward, B., S. Dutkiewicz, and M. Follows. 2014. Modelling spatial and temporal patterns in size-structured marine plankton communities: top-down and bottom-up controls. Journal of Plankton Research 36:31-47.

Ward, B., S. Dutkiewicz, O. Jahn, and M. Follows. 2012. A sizestructured food-web model for the global ocean. Limnology and Oceanography 57:1877-1891.

Ward, B., E. Marañón, B. Sauterey, J. Rault, and D. Claessen. 2017. The size dependence of phytoplankton growth rates: a trade-off between nutrient uptake and metabolism. American Naturalist 189:170-177.

Whittaker, R. 1972. Evolution and measurement of species diversity. Taxon 21:213-251.

Yoshida, T., L. Jones, S. Ellner, G. Fussmann, and N. Hairston. 2003. Rapid evolution drives ecological dynamics in a predator-prey system. Nature 424:303-306.

\section{References Cited Only in the Online Appendixes}

Droop, M. 1973. Some thoughts on nutrient limitation in algae. Journal of Phycology 9:264-272.

Grover, J. 1991. Resource competition in a variable environment: phytoplankton growing according to the variable-internal-stores model. American Naturalist 138:811-835.

Monod, J. 1949. The growth of bacterial cultures. Annual Reviews in Microbiology 3:371-394.

Morozov, A. 2010. Emergence of Holling type III zooplankton functional response: bringing together field evidence and mathematical modelling. Journal of Theoretical Biology 265:45-54.

Associate Editor: Spencer R. Hall Editor: Judith L. Bronstein

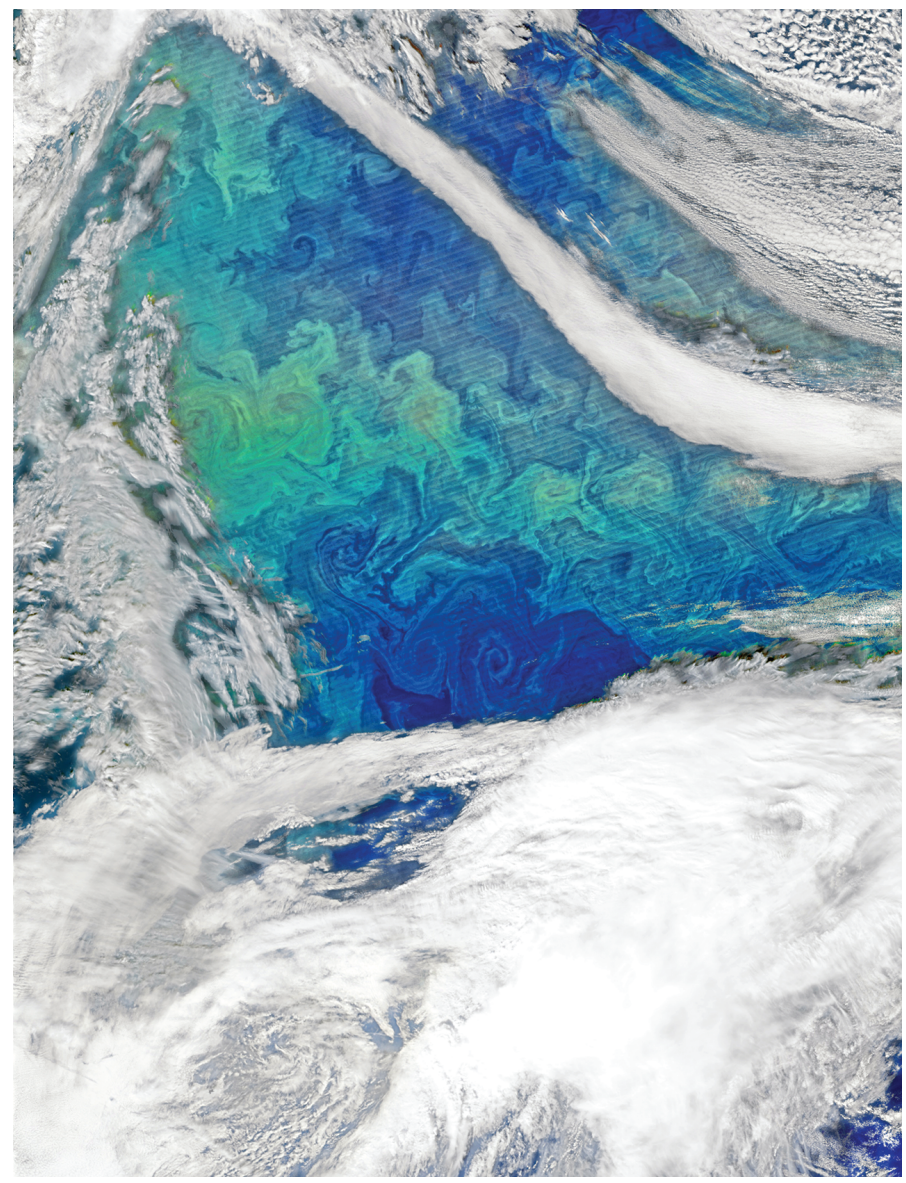

Satellite image from the visible Infrared Imaging Radiometer Suite (VIIRS) on the Suomi NPP NASA satellite illustrating a phytoplankton bloom in the North Atlantic. The ocean is artificially "colored" by plankton communities, detected using remote sensing of water reflectance. This image shows nicely the interaction between ocean biology and physics. Photo credit: Norman Kuring, NASA. 